\title{
Effects of Cochlear Implantation on Vestibular Pathway: Follow up Study in Cochlear Implant Children
}

\author{
Nagwa M Hazzaa ${ }^{1}$, Adel I Abdel Maksoud ${ }^{1}$, Lobna H Khalil ${ }^{1 *}$, Hassan A Wahba ${ }^{2}$ and Iman M Galal ${ }^{1}$ \\ ${ }^{1}$ Department of Otolaryngology, Audiology Unit, Ain Shams University, Egypt \\ ${ }^{2}$ Department of Otolaryngology, Ain Shams University, Egypt
}

Submission: June 10, 2017; Published: June 21, 2017

*Corresponding author: Lobna H Khalil, Department of Otolaryngology, Audiology Unit, Ain Shams University, Abbasia st., Egypt, Tel: 00201095041332; Email: Hamedlobna@yahoo.com

Abstract

Background: Many researchers studied the risk of vestibular dysfunction following cochlear implantation (CI). However, they were focused mainly on adults. Yet there is a need to study such effect on children especially that they may have significant vestibular impairment before CI implantation.

Objectives: So this study aimed to investigate the effect of CI on vestibular pathway by measuring VEMPs in children undergoing $\mathrm{CI}$ before and after surgery. Also, to study the possible effect of electrical stimulation from CI on vestibular pathway.

Methodology: The study group included forty children undergoing $\mathrm{CI}$ and 20 healthy children as control group. Pre-operative evaluation included detailed history, air conduction- cervical and ocular vestibular evoked myogenic potentials (cVEMPs and oVEMPs). Follow up was done at $1^{\text {st }}$ and $6^{\text {th }}$ months postoperatively for the implanted ears. To study the effect of CI stimulation, follow up cVEMPs testing was done without the device and through it using Insert earphone at the microphone with the device on.

Results: Abnormal cVEMPs responses were more frequent (in 55\% of cases) than abnormal oVEMPs (in 37\% of cases). On Follow up, only 2 cases had deterioration in oVEMPs responses compared to 10 cases in CVEMPs. cVEMPs responses through the device were detected after $1^{\text {st }}$ month in 7 (17\%) cases which increased to 17 cases(42.5\%) at $6^{\text {th }}$ month. Six cases had cVEMPs responses through the device though they had absent cVEMPs without it.

Conclusion: The saculo-vestibular pathway is likely to be compromised after CI surgery in children. On the other hand, CI might be useful in stimulation of saculo-vestibular pathway.

Abbreviations: VEMP: Vestibular Evoked Myogenic Potentials; CI: Cochlear Implantation; VP: Vestibular Pathway; VEMP: Vestibular Evoked Myogenic Potentials; FNS: Facial Nerve Stimulation

\section{Introduction}

Recently, there has been a growing awareness of vestibular dysfunction in children with hearing impairment. Published reports have shown that vestibular dysfunction was found in $20-70 \%$ of children with hearing loss of different etiologies [1]. Although cochlear implantation is now considered an effective and safe procedure, the potential effects on vestibular function are of clinical concern [2].Several mechanisms had been proposed such as: traumatic implantation of the electrodes, pressure fibrosis by implanted electrodes or extra-cochlear electrical stimulation caused by the implanted electrodes [3].

Different consequences on vestibular function may occur from post-operative electrical current provided by the implanted electrodes. Abdelghaffar and Elshazly [4] reported infrequent vertiginous sensations or imbalance every time the device was activated. On the contrary, Cushing et al. [5] reported that electrical stimulation of the vestibular system could provide some usable vestibular cues. Most of the studies have focused primarily on the adult population. Moreover, pediatric CI candidates may already have significant vestibular impairment before implantation as a result of underlying inner ear pathology. Accordingly, this study was designed to investigate the effect of CI on vestibular pathway by measuring Vestibular evoked myogenic Potentials (VEMPs) in CI children before and after surgery. In addition to study the possible effects of electrical stimulation from CI on vestibular pathway.

\section{Subjects and Methods}

This study that was carried out in the Audiology unit, ENT department, Aim Shams University. The procedures followed 
were ethically approved by the ENT Department Board. Caregivers/ parents of participated children in this study were informed and they gave their consent prior to the study.

\section{Subjects}

a. Study group included forty children undergoing CI. They had severe to profound sensorineural hearing loss of different etiologies ( 25 females, 15 males). Their age ranged from 3 -14years (mean 5.7 \pm 2.5 ). All children underwent cochlear implantation with same operational technique by the same surgery team.

b. Control group included twenty healthy children of matched gender ( 12 females, 8 males), age ( 4 -13years, mean $6.6 \pm 2.2$ ) and had no history of ear symptoms, vestibular insult or neurological disorders. Exclusion criteria: children with preoperative neurological and visual disorders.

\section{Methods}

\section{Preoperative evaluation}

Detailed history was taken from all caregivers/ parents of both the study \& control groups. It included: history of the motor milestones development, history of hearing loss, medical history, previous ototoxic/ vestibulotoxic drug intake and family history of hearing loss or consanguinity. Otologic examination and Middle ear functions were assessed using Madsen tympanometry model Zodiac 901. Air conduction cervical and ocular vestibular evoked myogenic potentials (cVEMPs and oVEMPs) were examined using four- channel evoked measuring system, ICS Charter EP 200.

Cervical VEMPs (cVEMPs): Gold surface electrodes were applied, with active recording electrode placed at upper third of sternocleidomastoid muscle ipsilateral to the stimulated ear, the reference electrode was placed on the upper sternum and the ground electrode was placed on the forehead. The skin was cleansed with alcohol prior to electrode placement. The electrode impedance was kept under $5 \Omega$. Monaural alternating $500 \mathrm{~Hz}$ tone burst (rise $/$ fall time $=1 \mathrm{~ms}$, plateau time $=2 \mathrm{~ms}$ ) were presented at $95 \mathrm{dBnHL}$ using calibrated EAR 3A insert earphones at $5 \mathrm{~Hz}$ for 150 stimuli.

The response was amplified and bandpass-filtered from 10 $\mathrm{Hz}$ to $1 \mathrm{kHz}$ with a recording epoch of $100 \mathrm{msec}$. Background electromyographic activity was monitored for consistent tonic contraction. Two traces from each side were obtained while the subject was sitting with the head rotating sideways toward one shoulder activate the sternocleidomastoid muscle. The initial positive negative biphasic waveform comprised peaks P13-N23. The latencies of peaks P13 and N23, amplitude P13-N23were measured.

Ocular VEMPs (oVEMPs): Gold surface electrodes were applied with active non-inverting electrode was placed $1 \mathrm{~cm}$ centered infra-orbital contralateral to the recorded ear and the reference electrode was placed on the chin. The ground electrode was placed on forehead [6]. The electrode impedance was kept under $5 \Omega$. The child was seated and instructed to keep his head at midline and gaze up at a fixed target (eg. stationary pictures or a toy) positioned 30 -35 degrees upward at the midline. Acquisition of about 100-150 sweeps. The EMG signals were amplified and band pass filtered between 10 and $1000 \mathrm{~Hz}$. Acoustic stimuli were the same as cVEMPs test. The analysis time for each response of $50 \mathrm{~ms}$. The initial negative positive biphasic waveform comprised peaks NI and PI. Two runs were performed. VEMPs were termed absent when the biphasic waveform was lacking. The latencies of peaks nI and pI amplitude nI-pI were measured.

\section{Postoperative follow up}

i. Follow up cVEMPs and oVEMPs was done for the implanted ears of study group at the end of the $1^{\text {st }}$ and the $6^{\text {th }}$ month postoperatively.

ii. CVEMPs testing through the CI was done using same recording parameters but sound stimulation via Insert earphone was pointed at the the level of microphone of the sound processor when the device was on [7].

\section{Statistical Analysis}

IBM SPSS statistics (V. 22.0, IBM Corp., USA, 2013) was used for data analysis. Mean and Standard Deviation (SD) were calculated. Paired ' $t$ ' test was used for two dependent means, Student ' $t$ ' test was used for two independent means with normal distribution while a comparison between two independent groups for non-parametric data was performed using Wilcoxon Rank Sum test. Ranked Spearman correlation test was used for non-parametric data. $\mathrm{P}<0.05$ was considered significant. Chisquare test for correlation between qualitative data.

\section{Results}

Demographic data distribution: There was no statistical difference as regards age and gender distribution between control and study groups ( $\mathrm{P}>0.05)$. The most common cause of hearing loss was Heredofamilial (Table 1).

Table 1: Distribution of different etiologies of hearing loss in the study group.

\begin{tabular}{|c|c|}
\hline Etiology & No (\%) \\
\hline Heredofamilial & $16(40 \%)$ \\
\hline Unknown & $13(32.5 \%)$ \\
\hline Heredofamilial + Postfebrile & $3(7.5 \%)$ \\
\hline Heredofamilial+ Neonatal insult & $2(5 \%)$ \\
\hline Waardenberg syndrome & $2(5 \%)$ \\
\hline Ototoxicity & $2(5 \%)$ \\
\hline Perinatal insult & $1(5 \%)$ \\
\hline
\end{tabular}

Preoperative findings: History of delayed walking was reported by the parents in $(8 / 40) 20 \%$ of cases. In addition four cases $(10 \%)$ had difficulties while walking unsupported or in dim light and had repeated unexpected falls. 


\section{Global Journal of Otolaryngology}

cVEMPs results: Abnormal cVEMPs was recorded in 22/40 (55\%) children. In 15 children (37.5\%) was bilateral and unilateral in $7(17.5 \%)$. Of the implanted ears, it was absent in $15 / 40$ (37.5\%) ears. Delayed latencies and/or lowered amplitude was in $7 / 40$ (17.5\%) ears. There was significant difference between control and the study group regarding cVEMPs parameters (P13 latency and P13-N 23 amplitude) (Table 2).

Table 2: Comparison between control and study groups regarding different cVEMPs and oVEMPs parameters.

\begin{tabular}{|c|c|c|c|c|c|}
\hline \multirow[b]{2}{*}{ cVEMPs } & \multirow[b]{2}{*}{$\begin{array}{c}\text { Control } \\
(\text { no. }=20)\end{array}$} & \multicolumn{3}{|c|}{ Study group* } & \multirow[b]{2}{*}{$\mathbf{p}$} \\
\hline & & $\begin{array}{l}\begin{array}{c}\text { Non- } \\
\text { Implanted } \\
\text { ears }\end{array} \\
\text { Mean (SD) }\end{array}$ & $\mathbf{p}$ & $\begin{array}{l}\text { Implanted } \\
\text { ears } \\
\text { Mean (SD) }\end{array}$ & \\
\hline P13 (ms) & $14.1(0.7)$ & $14.8(3.7)$ & $<0.01$ & $15.1(1.8)$ & $<0.01$ \\
\hline $\begin{array}{l}\text { N23 } \\
(\mathrm{ms})\end{array}$ & $21.3(2.4)$ & $21.2(5.1)$ & $>0.05$ & $21.7(2.4)$ & $>0.05$ \\
\hline $\begin{array}{c}\text { P13-N23 } \\
\text { (uV) }\end{array}$ & $133.5(54.8)$ & $102.7(67.2)$ & $<0.01$ & $105.4(67.2)$ & $<0.01$ \\
\hline \multicolumn{6}{|c|}{ oVEMPs } \\
\hline $\mathrm{n} 1$ (ms) & $10.6(1.2)$ & $11.6(1.1)$ & $>0.05$ & $10.9(1.04)$ & $>0.05$ \\
\hline p1 (ms) & $15.2(1.1)$ & $15.6(1.3)$ & $>0.05$ & $16.06(1.9)$ & $>0.05$ \\
\hline $\begin{array}{l}\text { n1-p1 } \\
\text { (uV) }\end{array}$ & $12.4(5.8)$ & $5.8(10.6)$ & $>0.05$ & $14.2(11.1)$ & $>0.05$ \\
\hline
\end{tabular}

*Study group (no.): cVEMP (no.=40) oVEMP(no.=29)

oVEMPs results: The test was done for $29 / 40$ of the study group. It couldn't be done in $11 / 40$ (27.5\%), younger age (3-4 years old), as they couldn't maintain the upward gaze efficiently to elicit the response. Abnormal OVEMPs was recorded in 11/29 $(37.9 \%)$ children. In $(8 / 29)$ children $(27.58 \%)$ were bilateral and unilateral in 3 (10.34\%).

Of the implanted ears, it was absent in $7 / 29$ (24.13\%) ears. Delayed latencies and/or lowered amplitude was in 4 (13.79\%). There was no significant difference between control and the study group regarding mean of oVEMPs response (n1 latency and n1-p1amplitude) (Table 2). There was highly significant correlation between history of delayed walking symptom and abnormal cVEMPs responses $(\mathrm{P}=0.00)$ and with abnormal oVEMP responses $(\mathrm{p}=0.03)$.

Postoperative findings: The same 4 cases with imbalance preoperatively remained with the same complaint postoperatively. Additional case had postoperative imbalance with difficulty in walking in dim light and bicycling which started 3 months postoperative. For implanted ear, the responses were divided into unchanged (stable) response and changed.

I. CVEMPs responses were unchanged (stable) was in $24 / 40$ ears (60\%). Changed responses were found in 16/40 (40\%). Six of them (15\%) showed temporarily absent response that was recovered at $6^{\text {th }}$ month, while the other $10(25 \%)$ showed consistent absent response at $6^{\text {th }}$ months postoperatively.
II. OVEMPs responses were unchanged (stable) response in $27 / 29$ ears (93.1\%). Changed responses was only in $2 / 29$ (7\%) ears. Both had preoperative normal response. One of them had delayed response at $1^{\text {st }}$ month postoperatively and the other had absent response at $6^{\text {th }}$ month. Detailed distribution of oVEMP responses in the implanted ear pre and postoperatively ( 1 \& 6 months) follow up are shown in (Table 3). There was no significant difference between preoperative, 1 and 6 months post-operartive VEMPs (oVEMPs and cVEMPs) parameters (Table 4).

Table 3: Distribution of VEMPs follow up changes in the study group.

\begin{tabular}{|c|c|c|c|}
\hline Preoperative & $\begin{array}{c}1 \mathrm{~m} \\
\text { Postoperative }\end{array}$ & $\begin{array}{c}6 \mathrm{~ms} \\
\text { Postoperative }\end{array}$ & No. $(\%)$ \\
\hline \multicolumn{4}{|c|}{ Unchanged (Stable) response: cVEMPs } \\
\hline Normal & Normal & Normal & $6(15 \%)$ \\
\hline Abnormal & Abnormal & Abnormal & $3(7.5 \%)$ \\
\hline Absent & Absent & Absent & $15(37 \%)$ \\
\hline \multicolumn{3}{|c|}{ Total } & $24(60 \%)$ \\
\hline \multicolumn{4}{|c|}{ oVEMPs } \\
\hline Normal & Normal & Normal & $16(55 \%)$ \\
\hline Abnormal & Abnormal & Abnormal & $4(13.3 \%)$ \\
\hline Absent & Absent & Absent & $7(24.7 \%)$ \\
\hline \multicolumn{3}{|c|}{ Total } & $27(93 \%)$ \\
\hline \multicolumn{4}{|c|}{ Temporarily Changed response: cVEMPs } \\
\hline Normal & Absent & Normal & $3(7.5 \%)$ \\
\hline Delayed & Absent & Delayed & $3(7.5 \%)$ \\
\hline \multicolumn{3}{|c|}{ Total } & $6(15 \%)$ \\
\hline \multicolumn{4}{|c|}{ Permanent changed response: cVEMPs } \\
\hline Normal & Absent & Absent & $5(12.5 \%)$ \\
\hline Normal & Delayed & Absent & $2(5 \%)$ \\
\hline Normal & Normal & Delayed & $2(5 \%)$ \\
\hline Delayed & Absent & Absent & $1(2.5 \%)$ \\
\hline \multicolumn{3}{|c|}{ Total } & $10(25 \%)$ \\
\hline \multicolumn{4}{|c|}{ oVEMPS } \\
\hline Normal & Normal & Absent & $1(3.5 \%)$ \\
\hline Normal & Abnormal & Abnormal & $1(3.5 \%)$ \\
\hline \multicolumn{3}{|c|}{ Total } & $2(7 \%)$ \\
\hline
\end{tabular}

Table 4: Comparison between pre-operative and postoperative VEMPs prameters in the study group (implanted ears).

\begin{tabular}{|c|c|c|c|c|}
\hline cVEMPs & $\begin{array}{c}\text { Preoperative } \\
\text { Mean (SD) }\end{array}$ & $\begin{array}{c}\text { 1month } \\
\text { post } \\
\text { operative } \\
\text { Mean (SD) }\end{array}$ & $\begin{array}{c}\text { 6 months } \\
\text { post } \\
\text { operative } \\
\text { Mean (SD) }\end{array}$ & p \\
\hline P13(ms) & $15.1(1.8)$ & $16.23(3.29)$ & $15.62(3.09)$ & $>0.05$ \\
\hline N23(ms) & $21.7(2.4)$ & $22.47(4.47)$ & $23.21(5.15)$ & $>0.05$ \\
\hline Amplitude (uV) & $105.4(67.2)$ & $81.28(40.5)$ & $70.72(50.03)$ & $>0.05$ \\
\hline \multicolumn{5}{|c|}{ oVEMPs } \\
\hline n1 latency (ms) & $10.9(1.04)$ & $10.8(1.7)$ & $10.6(2.7)$ & $>0.05$ \\
\hline p1 latency (ms) & $16.06(1.9)$ & $16.3(2.8)$ & $13.8(4.2)$ & $>0.05$ \\
\hline Amplitude (uV) & $14.2(11.1)$ & $11.2(8.8)$ & $11.3(10.2)$ & $>0.05$ \\
\hline
\end{tabular}




\section{Global Journal of Otolaryngology}

\section{Distribution of cases that had cVEMPs response through the CI Device}

The total no of cases that had cVEMPs response through the device were 18/40 (45\%). Six of them (15\%) showed consistent response at 1 and 6 months pos-toperatively while eleven of them $(27.5 \%)$ showed response at $6^{\text {th }}$ month pos-toperatively. Only one showed response at $1^{\text {st }}$ month that disappeared at $6^{\text {th }}$ month. Interestingly 6 patients had response through the device although they initially did not have response without the CI. Facial nerve stimulation was reported in 7 cases, all of them had cVEMPs response through the device. There was no significant difference between cVEMPs parameters with and without the device (Table 5).

Table 5: Comparison between cVEMPs parameters with and without $\mathrm{Cl}$ device at $6^{\text {th }}$ month postoeratively $(n=11)$.

\begin{tabular}{|c|c|c|c|}
\hline & $\begin{array}{c}\text { without CI } \\
\text { Mean (SD) }\end{array}$ & $\begin{array}{c}\text { with CI } \\
\text { Mean (SD) }\end{array}$ & P \\
\hline P13(ms) & $15.2(2.5)$ & $16.6(2.8)$ & 0.09 \\
\hline N23(ms) & $22.6(4.7)$ & $25.4(5.8)$ & 0.15 \\
\hline Amplitude(uV) & $74.6(44)$ & $107(65.2)$ & 0.05 \\
\hline
\end{tabular}

\section{Discussion}

\section{Preoperative findings}

Children with abnormal responses in vestibular tests would show delay in acquisition of gross motor function [8]. In current study, $20 \%$ of children with severe sensorineural hearing loss (8/40) had delayed walking as reported by their parents. In addition to four cases $(10 \%)$ had difficulties while walking unsupported, or in dim light with repeated falls. These findings are In agreement with Masuda and Kaga [9] found that head control and independent walking were delayed in 28 of 97 (28.8 $\%$ ) children with severe hearing loss. Also, Inoue et al. [8] found that children who showed abnormal responses in vestibular tests showed delay in acquisition of gross motor function in comparison with the normal hearing peers.

The vestibular nuclei provide consistent input to the postural muscle motor neurons particularly during initial postnatal development in the initial 6-12 months of life. The vestibulospinal reflex - through the lateral vestibulospinal tract acts by synapsing directly with motor neurons innervating extensor muscles and indirectly through spinal cord interneurons. Accordingly, the developmental milestones such as walking would be delayed with abnormal vestibular system particularly the vestibulospinal reflexes [10].

\section{VEMPs findings}

The current study showed that hearing impaired children with variable etiologies had VEMPs abnormalities, (55\%) for cVEMPs and (37.9\%) for oVEMPs. Abnormal bilateral responses were more frequent than unilateral abnormalities. The predominant abnormality was absent response. In addition CVEMPs parameters showed significant prolonged P13 latency and lower P13-N23 amplitude compared to the control group. While OVEMPs response parameters showed prolonged mean of n1 latency but did not reach the significant difference with the control group. These findings points to that saccular dysfunction was more frequent than utricular dysfunction. The overall findings was symptomatically reflected in $(30 \%)$ of case as history of delayed walking or imbalance. Previous studies also found high percentage of abnormality in cVEMPs among hearing impaired children. Shall [10] found 21\% of children demonstrated absent cVEMPs response unilaterally, while $67 \%$ of children showed bilateral absent response. Jin et al. [11] demonstrated that cVEMP response was abnormal or absent in $50 \%$ of cases. To the best of the authors knowledge, no studies was found concerned with oVEMPs in hearing impaired children, except for $\mathrm{Xu}$ et al. [12] who found $71 \%$ hearing impaired children (22 of 31) had preserved oVEMP response before cochlear implantation.

The high prevalence of vestibular impairments in hearing impaired pediatric patients was explained by the close anatomical and phylogenetic relation between the cochlea and saccule, where they are closely related in terms of innervation and vascular supply. They share the continuous membranous labyrinth of the inner ear and function by means of similar receptor cells. So, it appears plausible that, whatever the cause of damage to the cochlea, the same agent could probably also damage the saccule [13]. Hence, it is reasonable to presume that many children with hearing impairment have concomitant vestibular abnormalities [11]. Meanwhile, the saccule is more vulnerable than utricle for affection in cases with SNHL would be due to the anatomical \& embryological proximity of the saccule to the cochlea. The vestibular disturbances are corrected through the process of compensation from proprioceptive, visual, and other sensory systems substitute for the absent peripheral vestibular input [14]. This may explain why only (30\%) of cases had delayed walking or imbalance.

\section{Postoperative findings}

Vertigo or unsteadiness is not an uncommon adverse effect of CI as stated by several studies. Filipo et al. [15] reported postoperative vertigenous episodes in $12 \%$ of adult patients. Bonucci et al. [16] reported worsening in vestibular symptoms in $5 \%$ of adult patients. This didn't agree with the present study where vestibular complaint as an adverse effect of CI operation was not present. As postoperative complaints was found in the same 4 cases who had preoperative imbalance. They had the same abnormalities in cVEMPs and oVEMPs tests as preoperatively. Only one child complained of imbalance postoperatively. The child was presented with imbalance and also inability to ride bicycle as she was used to do preoperatively. These symptoms started 3 months postoperative. It is worth mentioning that she had same abnormal findings in cVEMPs \& oVEMPs (bilateral absent responses). She developed blurring of vision and diminished visual acuity. So fundus examination was done 
revealed retinitis pigmentosa. The most probably diagnosis of this case was Usher's syndrome. From these findings CI couldn't be considered the main cause of deterioration in this case.

\section{Postoperative findings of cVEMPs}

In the present study, we have found stability of cVEMPs response in $60 \%$ and only $25 \%$ of children who have permanent deterioration in their respons in the $6^{\text {th }}$ months postoperatively. Among them 8/ 40 (20\%) had lost the response. There was non-significant difference between cVEMPs parameters among the cases at different test time among the cases with preserved response confirming the stability of their response post-implantation (Tables 4). The prevalence of postoperative vestibular hypofunction reported by previous studies ranged from $20-76 \%$ [16]. Studies as Ernst et al. [17] reported postoperative lost cVEMP responses in $42 \%$ of adult cases, where absence of cVEMP response changed from $36 \%$ preoperatively to $78 \%$ postoperatively. Bogle et al [18] demonstrated a change in the presence of the cVEMP response in children from $100 \%$ prior to implantation to $53 \%$ following surgery. Other studies reported less percentage of abnormality as Licameli et al. [19] showed postoperative absent response in $20 \%$ of cases. This wide range could be attributed to the variation among studies regarding the study group, types of electrodes, recording parameters and also operation technique.

This loss of response could be explained anatomically, as the saccule is the closest vestibular end organ to the basal turn of the cochlea, the location that research has previously demonstrated as the area most at risk for damage during implantation. This finding was in accordance with histopathological studies on temporal bones from patients who had been implanted during life. These studies demonstrated structural changes in the saccule mainly, followed by utricule, and semicircular canals [20]. However, the exact mechanism responsible for the vestibular deficits is not yet completely settled. We found that $6 / 40(15 \%)$ of cases had temporarily absent cVEMPs response in our study. The response was absent in the $1^{\text {st }}$ month but reappeared in the $6^{\text {th }}$ month postoperatively. Similarly this temporarily absence response was found in $28.5 \%$ of cases [21]. After an initial impairment, the partial or complete recovery of the vestibular responsiveness with time could be explained by reversible and mild insults inflammatory process following the surgery or perilymphatic imbalance that didn't result in permanent damage in the saccule. So that cVEMPs results should be cautiously interpreted during early months post CI.

\section{Postoperative results of oVEMPs}

Unlike cVEMP, oVEMPs showed higher stability in (93\%). Permanent deterioration at $6^{\text {th }}$ month post operatively was noted only in 2 cases $(7 \%)$. Few studies assessed utricular function but by measures other than oVEMPs. Basta et al. [22] evaluated utricular function 2 days before and 6 weeks after surgery by Subjective visual vertical test. They found that it remained unchanged. The utricular function was also measured using off vertical axis rotation. Xu et al. [12] reported higher percentage of utricular abnormality measured by oVEMPs in cochlear implant cases. They found that $71 \%$ of cases with preserved response preoperatively, reduced significantly to $19.2 \%$. They explained the presence of this high percentage of injury by the cochleostomy approach.

\section{Postoperative cVEMPs response through the CI Sound processor}

Since regular cVEMPs can't discriminate exactly between end organ versus neural pathway abnormality, cVEMP through the CI device was done in an attempt to find out whether CI had an influence on the neural pathway; inferior vestibular nerve. Our study results revealed that $17 / 40(42.5 \%)$ of cases had cVEMP response through the device at the $6^{\text {th }}$ month postoperatively. One patient $(2.5 \%)$ showed transient response at $1^{\text {st }}$ month. Wave latencies and amplitude through the CI did not differ than regular cVEMPs. Regarding the influence of co-stimulation as a result of $\mathrm{CI}$, there were no vertiginous symptoms during the study. However, 2 cases had complained of headache and 7 cases had facial nerve stimulation (FNS) when the device was turned on. All of them had CVEMPs response through the CI.

This was also found in Coordes et al. [7] study where 4 /26 (15\%) of adult cases had CVEMP response through the CI sound processor. The mechanisms underlying this finding remain speculative. It could be explained by the electric co-stimulation to the vestibular nerve. With the CI turned off, only acoustic stimulation was delivered, but with the cVEMP through CI turned on the acoustic stimulation changed to electrical stimulation in the inner ear. So the cVEMPs response could be caused by the electrical current which probably stimulated the inferior vestibular nerve. They also suggested an interaction of the CI electrode with adjacent nerves as the electrical co-stimulation of the facial nerve. Intraoperative electrically elicited response of the vestibulo-spinal reflex by the CI electrode; cVEMP has been demonstrated by Basta et al. [22] study. They found that the threshold of the apical electrode was lower compared to threshold of the basal electrode. This supported the hypothesis of inferior vestibular nerve co-stimulation by the CI, where electrodes of the apical cochlear part are in close proximity to the nerve. This leads to the assumption that the current spread is seemingly more focused to the inferior vestibular nerve upon apical electrode stimulation.

The current study also noted that among cases who had response through the device, $(2 / 7)$ in the $1^{\text {st }}$ month and $(6 / 10)$ in the $6^{\text {th }}$ month, had no response on the regular cVEMPs. This was also found by Jin et al. [11] who reported that $4 / 12$ children (33.3\%) showed CVEMPs through cochlear implants activation. Among these four children, 2 showed no CVEMPs. In addition, Jin et al. [23] found that 10/20 children, who showed no cVEMPs response with the CI off, had cVEMPs responses through the CI. They suggested that the inferior vestibular nerve must be intact, 
although the functions of the saccule were lost in CI patients. In support to this, a human temporal bone pathological study demonstrated that Scarpa's ganglion cell count in the operated ear was the same as that in the non-operated ear; however, saccular collapse was only seen in the operated ear. Our study revealed that all cases suffered from FNS had CVEMPs response through the CI. So the presence of the FNS might predict the co-presence of the vestibular nerve stimulation. However, this needs further research.

\section{Conclusion}

Saculo-vestibular pathway is likely to be compromised after CI surgery in children. On the other hand, CI might be useful in stimulation of saculo-vestibular pathway. So we recommend that cVEMPs should be a part of the pre-operative evaluation of CI children and their monitoring post-operatively. Also, VEMPs results should be considered for the selection of implanted ear (affected ear).

\section{References}

1. Singh S, Gupta R K, Kumar P (2012) Vestibular Evoked Myogenic Potentials in Children with Sensorineural Hearing Loss. Int J Pediatr Otorhinolaryngol 76(9): 1308-1311.

2. Licameli G, Zhou G, Kenna M (2009) Disturbance of Vestibular Function Attributable to Cochlear Implantation in Children. Laryngoscope 119(4): 740- 745.

3. Katsiari E, Balatsouras DG, Sengas J, Riga M, Korres GS Xenelis J (2013) Influence of cochlear implantation on the vestibular function. Eur Arch Otorhinolaryngol 270(2): 489-495.

4. Abdelghaffar H, Elshazly M (2011) Cochlear Implants in Children with Vestibular Hypofunction. Egyptian Journal of Ear, Nose, Throat and Allied Sciences 12: 49-52.

5. Cushing SL, Papsin BC, Gordon K A (2006) Incidence and Characteristics of Facial Nerve Stimulation in children with Cochlear Implants. Laryngoscope 116(10):1787-1791.

6. Piker E, Jacobson GP, McCaslin DL, Hood LJ (2011) Normal characteristics of the ocular VEMP. J Am Acad Audiol 22(4): 222-230.

7. Coordes A, Basta D, GÖtze R, Scholz S, Seidl R, et al. (2012) SoundInduced Vertigo After Cochlear Implantation. Otol Neurotol 33(3): 335-342.

8. Inoue A, Iwasaki S, Ushio M, Chihara Y, Fujimoto C, et al. (2013) Effect of vestibular dysfunction on the development of gross motor function in children with profound hearing loss. Audiol Neurootol 18(3): 143-151.

9. Masuda T, Kaga K (2014) Relationship between Acquisition of Motor Function and Vestibular Function in Children with Bilateral Severe Hearing Loss. Acta Otolaryngol 134(7): 672-678.
10. Shall MS (2009) The Importance of Saccular Function to Motor Development in Children with Hearing Impairments. International Journal of Otolaryngology 20: 1-5.

11. Jin J, Nakamura M, Shinko Y, Kaga K (2006) Vestibular Evoked Myogenic Potentials in Cochlear Implant Children. Acta OtoLaryngol 126(2): 164-169.

12. Xu XD, Zhang XT, Zhang Q, Hu J, Chen YF, et al. (2015) Ocular and Cervical Vestibular-evoked Myogenic Potentials in Children with Cochlear Implant. Clin Neurophysiol 126(8): 1624-1631.

13. Schwab B, Kontorinis G (2011) Influencing Factors on the Vestibular Function of Deaf Children and Adolescents - Evaluation by Means of Dynamic Posturography. The Open Otorhinolaryngology Journal 5: 1-9.

14. Suarez H, Angeli S, Suarez A, Rosales B, Carreara X., et al. (2007) Balance Sensory Organization in Children with Profound Hearing loss and Cochlear Implants. Int J Pediatr Otorhinolaryngol 71(4): 629-637.

15. Filipo R, Patrizi M, La Gamma R, D’Elia C, La Rosa G, et al. (2006) Vestibular Impairment and Cochlear Implantation. Acta Oto Laryngologica 126(6): 1266-1274.

16. Bonucci AS, Filho OA, Mariotto LF, Amantini RB, Alvarenga KF (2008) Vestibular Functions in Cochlear Implant users. Rev. Bras J Otorrinolaringol 74(2): 273-278.

17. Ernst A, Basta D, Seidl RO (2005) Management of Posttraumatic Vertigo. Otolaryngol Head Neck Surg 132(4): 554-558.

18. Bogle JM, Yoshinaga Itano C, Ackley RS (2010) The effect of Cochlear Implantation on the Vestibular Evoked Myogenic Potential Response in Children and Adult population. MD thesis. University of Colorado.

19. Licameli G, Zhou G, Kenna M (2009) Disturbance of Vestibular Function Attributable to Cochlear Implantation in Children. Laryngoscope 119(4): 740- 745.

20. Handzel O, Burgess BJ, Nadol JB (2006) Histopathology of the Peripheral Vestibular System after Cochlear Implantation in the Human. Otol Neurotol 27(1): 57-64.

21. Jacot E, Abbeele V, Debre HR, Weiner Vacher SR (2009) Vestibular Impairments pre- and post-cochlear Implant in Children. International Journal of Pediatric Otorhinolaryngology 73(2): 209217.

22. Basta D, Todt I, Goepel F, Ernst A (2008) Loss of saccular Function after Cochlear Implantation: The diagnostic Impact of Intracochlear Electrically Elicited Vestibular Evoked Myogenic Potentials. Audiol Neurotol 13(3): 187-192.

23. Jin Y, Shinjo Y, Akamatsu Y, Ogata E, Nakamura M, et al. (2008) Vestibular Evoked Myogenic Potentials Evoked by Multichannel Cochlear Implant - influence of C levels. Acta Otolaryngol 128(3): 284-290. 
This work is licensed under Creative Commons Attribution 4.0 License DOI: $10.19080 /$ GJO.2017.08.555743
Your next submission with Juniper Publishers will reach you the below assets

- Quality Editorial service

- Swift Peer Review

- Reprints availability

- E-prints Service

- Manuscript Podcast for convenient understanding

- Global attainment for your research

- Manuscript accessibility in different formats ( Pdf, E-pub, Full Text, Audio)

- Unceasing customer service

Track the below URL for one-step submission https://juniperpublishers.com/online-submission.php 